This item was submitted to Loughborough's Research Repository by the author.

Items in Figshare are protected by copyright, with all rights reserved, unless otherwise indicated.

\title{
Education and internal migration
}

PLEASE CITE THE PUBLISHED VERSION

http://www.routledge.com/9781472452467/

\section{PUBLISHER}

Ashgate/Routledge

VERSION

AM (Accepted Manuscript)

\section{PUBLISHER STATEMENT}

This work is made available according to the conditions of the Creative Commons Attribution-NonCommercialNoDerivatives 4.0 International (CC BY-NC-ND 4.0) licence. Full details of this licence are available at: https://creativecommons.org/licenses/by-nc-nd/4.0/

\section{LICENCE}

CC BY-NC-ND 4.0

\section{REPOSITORY RECORD}

Smith, Darren P., and Heike Jons. 2019. "Education and Internal Migration". figshare. https://hdl.handle.net/2134/25433. 
Please cite chapter as follows:

Smith, DP and Jons, H (2015) Education and internal migration. In Smith, DP, Finney, N, Halfacree, K, Walford, N (eds) Internal Migration: Geographical Perspectives and Processes. Farnham: Ashgate, pp.47-63.

Chapter 4: Education and Internal Migration

Darren P. Smith and Heike Jöns

\section{Introduction}

Tellingly, Champion and Fielding's (1992a) edited book does not include a dedicated chapter on the theme of 'Education and Migration'. When compared with current academic debates on social change in the UK, which emphasize the links between education and social inequalities (e.g. Johnston, et al., 2008; Dorling, 2013), the absence of a focus on education (throughout the chapters) in 1992 is striking. Two decades later, this has changed because Fielding's (2012) conceptual treatment of 'Internal Migration' has centrally embedded 'Higher Education' in a diagrammatic representation of internal migration, placing it in a prominent way alongside its two counterparts of 'Labour Migration' and 'Housing'. 'Journey to school' is also represented as a form of migration - characterised by limited duration of stay (1-9 hours) and minimal distance travelled (p. 5).

At the same time, national media discourses (e.g. Webb, 2010) tend to represent the residential moves of families to gain access to prized nursery, school, or higher education places as a seemingly common-place practice. Middle-class individuals and families are often portrayed as prioritising high-quality schooling/higher education experiences and credentials for future social mobility and well-being. It would appear that moving to reside in the 'right neighbourhood' in order to access the 'right education' is increasingly encapsulated within inter-linked residential and migration decision-making processes of many middle class individuals and families (Butler and Hamnett, 2007). A recent Nationwide housing report found, for instance, that households are willing to pay $10 \%$ more for comparative property in neighbourhoods that have perceived good schools (Johnson, 2013).

On the whole, the relative lack of attention to education and migration within Champion and Fielding's (1992a) collection suggests that education-induced relocations were not a distinctive constituent of internal migration processes in the UK before the 1990s. Equally, in 1992 it would have been difficult to predict the unprecedented changes that have unfolded within school (Holloway and Pimlott-Wilson, 2012) and higher education systems (Hoare and 
Johnston, 2011). Indeed, as the range of educational spaces and experiences have been transformed by the incessant impulses of neoliberalisation (Holloway, et al., 2010) and the rise of 'performance evaluation cultures' and 'supposed choice', the resultant geographies of 'education migrants' (albeit families with children or young, single, university students) are one of the most conspicuous signifiers of contemporary urban and rural change in the UK (Smith, Rerat and Sage, 2014).

Yet, the sub-national migrationary dynamics of individuals and families moving for educationrelated factors has, to date, not been fully acknowledged in an explicit way, or effectively conceptualized within geographic or migration studies scholarship (for exceptions see Hoare and Corver, 2010; Dennett and Stillwell, 2010a, 2010b). This is despite numerous studies of urban change that inherently capture the internal migration of distinct social groups for education-related reasons, as epitomized, for instance, by studies of studentification (Munro Turok and Livingston, 2009). In a sense, population movements in these studies often appear to be treated as a taken-for-granted backdrop; a necessary condition of the main issues that are under investigation, such as the impacts of parental school choice on local housing markets and neighbourhood cohesion (Butler, et al., 2007), or the connections between university student populations and urban change (Hubbard, 2009).

This chapter, therefore, argues that there is merit in taking more seriously, and conceptualising more explicitly, how, why, where and when individuals and families move sub-nationally to access a range of (exclusive) educational spaces and experiences at different phases of the lifecourse. We would argue that these questions are pressing in light of migration becoming a more normative social practice that is tied to realising 'sought-after' educational experiences (Smith, Rerat and Sage, 2014). From a geographical perspective, this is important given the formation of concentrated and segregated social geographies that are being created by a variety of sub-national education-related population movements, as well as the reinforcement of education-related institutional prestige (high performing, exalted schools and universities) in specific enclaves, towns, cities and villages (Smith and Hubbard, 2014).

The following chapter is divided into three sections. The first section focuses on school education, and considers the impacts of key legislative changes that have shaped parental choice of schools, and notions of being a 'good parent', and led to the entrenchment of more exclusive school catchment areas and housing markets. The second section considers the impacts of the post-1990 expansion of higher education from a sub-national migration perspective. Finally, we offer some concluding remarks and point to a research agenda for geographies of education and migration in the current fluid context, where educational systems are being recast by conditions of neoliberalisation and globalisation. 
Our perspective of education is, in part, aligned to Holloway and Jöns' (2012, p. 482) view of 'formal education systems from pre-school to tertiary education' because this allows for a rare comparative perspective on the role of migration for education at different stages of the lifecourse (for an international context, see Waters, 2012). Of course, it is important to acknowledge that there are numerous 'other' spaces of education that fall outside our focus, such as informal education spaces (Mills and Kraftl, 2014), the purchasing of private education (Taylor, 2002), and home schooling (Kraftl, 2013). As an exploration of the full range of educational experiences and spaces is beyond the scope of this chapter, we wish, at least, to stress that all dimensions of education may have important migrationary implications that warrant attention elsewhere.

\section{Accessing the 'right' school: the power of school catchments and parental choice/constraint}

During the last two decades, a well-established scholarship has formed which exposes the social inequalities and social class-based differences stemming from the 1988 Education Act (Reay and Lucey, 2000), the state-scripted notions of so-called responsible, 'good parenting' (The Parent's Charter, Department for Education, 1991) (Oria, et al., 2007), and, more recently, the 2006 Education and Inspections Act (Burgess, et al., 2011). It is fair to say that Ball, Bowe and Gewirtz's (1995, p. 52) evocative claim that 'sociological understanding of choice and choice-making [for schools] is woefully underdeveloped' is no longer pertinent. By contrast, geographers and migration scholars could still devote more attention to these issues, and, in particular, to the spatial processes and patterns of school choice and constraint (see Dobson and Stillwell, 2000; Taylor, 2009; Butler and Hamnett, 2007).

This is not to argue that education systems in the UK have not been historically founded on some form of market differentiation, and given rise to geographic inequalities (Marsden, 1987). However, one of the common themes that has emerged from scholarship in this field is that the 1988 Education Act has amplified the ways in which differential access to school education (re)produces social (dis)advantage and privilege (Ball, Bowe and Gewirtz, 1996). Key factors here include: the formalization of parental choice and selection in the schooling of children (Ball, 1993), and the reinforcement of hierarchies of schools based on performance league tables and reports (Allen and Burgess, 2013), tightly-defined school admission procedures and rules, and the allocation of scarce places in line with published official school capacity. This viewpoint is epitomized by Butler, et al.'s (2007, p. 9) assertion that: 'although nominally the 1988 Education Act offers parental choice, the reality is one of a market in which there is great competition for popular choices'. 
Framed by this legislative terrain of choice and competition (Reay and Ball, 1998), sociospatial divisions between social groups would appear to be widening as middle-class parents deploy higher levels of economic and cultural capital in a quest to ensure their children attend the most popular (i.e. highest performing and renowned) schools (see Allen, Burgess and McKenna, 2012 for a comprehensive discussion of school admission processes/catchment areas for state-maintained schools). Ball, Bowe and Gewirtz (1995) demonstrate, for instance, that middle class parents are the most active 'choosers' of particular schools for their children. Moreover, Ball, Bowe and Gewirtz (1995) comment that middle class parents are increasingly embroiled in 'circuits of education/schooling', whereby a strategic plan is scripted and enacted to ensure that their children access the highest quality education at all phases of their education lifecourse, often from childcare to university. The effectiveness of this social practice is, in part, facilitated by the exploitation, to make well-informed decisions, of 'hot grapevine knowledge' that is socially embedded within local networks of middle-class households, and complementing the 'cold official knowledge' that is disseminated by schools and other relevant organisations such as OFSTED (i.e. league tables, examination results). The 'hot' knowledge is derived from: 'drawing upon impressions and experiences of friends, neighbours, and relatives in their choice-making' (Ball and Vincent, 1998, p. 378). In this way, middle-class households are able to take advantage of the 'education market' to reproduce their class advantage (Crozier, Reay and James, 2011). This is in stark contrast to views of working-class parents, who are often seen as being ambivalent to the education market place for a variety of reasons, including limited resources and lack of information, which underpins growing educational inequalities in society (Reay and Ball, 1997).

Other studies which evidence these connections between education and geographies of privilege/disadvantage include Burgess et al.'s (2011, p. 531) analysis of the Millennium Cohort Study, which reveals that 'higher socio-economic status (SES) pupils being more likely to be accepted into (nearer) more advantaged schools'. Likewise, from their analyses of Eligibility for Free School Meals datasets, Burgess and Briggs (2009, p. 639) identify that: 'Children from poorer families are significantly less likely to go to good schools'. Their findings reveal that 'the single most important factor lying behind this differential chance is location', with a 'clear link between poverty, location and school quality' (p. 647).

Although such education-related aspirations and motivations to access high-quality schooling is overwhelmingly specific to the middle classes, it is also important to note that inequalities in the education market cross-cut ethnic/racial, gender, cultural and demographic axes of difference (Finney, 2011), although there are limited studies on these 
intersecting social differences and inequalities in the education market (see Butler, Hamnett and Ramsden, 2013 for an exception).

Within this broad disciplinary scholarship, to date, the migrationary dimensions of families seeking higher-quality school education, or the growing influence of education-related factors within wider residential decision-making processes have been under-researched. This is despite Dobson and Stillwell's (2000, p. 395) landmark critique of migration studies for paying 'scant attention to the location and perception of schools as possible influence' on the (non)migration of families with children; a trend which is subsequently borne out by their analyses of 1991 UK census migration datasets. As Dobson and Stillwell suggest, perceptions about the variable qualities of schools 'have become a much more significant factor both in residential location, for those in a position to choose, and even in decisions about whether to move at all' (p. 396).

Within this context, it is possible to distinguish between some general education-related migration flows, which include decisions to either:

i) Undertake relatively long daily 'commutes' (children and/or parents) to access education spaces in places at a relatively long distance from the family home, which are deemed to be within reach;

ii) Relocate the household within the current town, city or village of residence, or 'upsticks' and move to a different town, city or village, or;

iii) 'Stay-put' and access the 'best possible' educational experience within the current place of residence, even if it is in the form of sending children to boarding schools.

We adopt this distinction between different forms of education-related migration to structure the remainder of this chapter.

\section{Moving within towns and cities 'to get the right school': internal migration?}

According to Butler (2003), the perceived necessity to gain entry into competitive educationmarket places within London have stimulated some middle class parents and children to move across boroughs of London on a daily basis to access the 'right' school within the state and private education sectors. Equally, it is highly probable that similar patterns of movement are evident in the other large metropolitan centres and towns/cities of the UK (Bridge, 2006).

Describing these education-oriented daily population movements as 'a lot of to-ing and froing at the beginning and end of the school day' (p. 2476), Butler (2003) contends that these patterns 'have been greatest [in large, dense, urban areas] simply because of the limitations 
of distance elsewhere' (p. 2480). Implicitly exposing the importance of circuits of education, Butler reveals in his study of gentrified neighbourhoods in North London that middle class parents 'feel forced to send their children out of the borough to state selective or independent schools not just at secondary but also, to a lesser extent, at primary level-partly because the local state primary schools are unable to prepare their children for the Common Entrance examination used by the private secondary school' (p. 2481). As a consequence, Butler (2003) highlights how some middle class parents are 'sending their children at the age of seven or eight to the private feeder preparatory schools to prepare them for the ferocious competition to get into these schools' (p. 2483). These trends are evidenced by Butler, Hamnett and Ramsden (2007) in their analyses of Pupil Level Annual School Census data, expressing that 'the very best performing schools are attracting students from a greater distance' (p. 25), from 'a wide area and from the 'better' postcodes' (p. 26) (see Harland and Stillwell, 2010; Hamnett and Butler, 2011).

These practices of inter-Borough moves within London are undertaken despite Butler (2003) revealing that 'their (respondents of Barnsbury) preference would be to educate their children both locally and in the state sector' (p. 2481). By contrast, Butler contends, that, historically, 'the initial gentrifiers [of the 1980s and 1990s] educated their children in the local schools at all levels' (p. 2476). However, Butler (2003) argues that contemporary gentrifier households are often the 'minority' population (statistically) within 'cosmopolitan' neighbourhoods, and that local education is often deemed not appropriate for their children due to the high population diversity of the global city.

In a follow-up study, Butler, Hamnett and Ramsden (2007: 8) postulate that 'despite a rhetoric in favour of multiculturalism, London's (white) middle classes, for the most part, do not wish their children to be educated in such schools' (see also Hamnett, Butler and Ramsden, 2013). Empirically, from research with gentrifiers in Islington, Butler (2003) finds that '[n]ot a single respondent from the interviews had a child at a secondary school in Islington' (p. 2476).

One of the main consequences of these education-led movements of middle class households is the widening social and spatial division between children from different social classes and backgrounds. Moreover, Butler (2003) asserts that 'moving for school', 'confirms the pattern of a tight middle-class settlement in which many of the children, having gone to the same nursery and primary schools, often continued to the same secondary schools elsewhere in north London' (p. 2483), and, as a result: 'Children inhabit entirely separate social spaces from other, and more disadvantaged, groups' (p. 2469). These links are borne out in McDowell, et al.'s (2006) study of middle class strategies for childcare, which provides insights of similar daily patterns of movement for middle-class parents, describing how: 
'children are ferried out of the borough and/or to private nurseries and schools' (p. 2170). It is argued by McDowell et al. that '[it] is no longer correct to assume automatically that even pre-school care occurs in the same neighbourhood as the family home' (p. 2166) (Vincent and Ball, 2001; Vincent, Ball and Kemp, 2004).

The deepening entrenchment of socio-spatial divisions of children, in part, is bound-up with broader, intentional middle-class strategies to 'separate themselves from the 'local' community' (Butler, 2003, p. 2476), and interact with 'people like us'. In this sense, population movements to facilitate access to exclusive education spaces have the potential to be utilised as a mechanism for children to 'only mix with other middle-class children and the parents' social and leisure activities overwhelmingly involve people like themselves' ( $p$. 2484).

Local class-specific contingencies and cultures, or what Raveaud and van Zantent (2006) term 'local normative frameworks' are important here, making 'certain choices more frequent and legitimate than others as parents look to other parents as reference groups to decide how to act, to construct their choices and to reassure themselves about their consequences' (p. 109). For middle class households, it would appear that education-led movements are bound-up within local normative frameworks to ensure that children access the highest possible quality of education that is logistically available in their residential environs. There are parallels between these education-led movements and Savage's (2010) thesis of 'elective belonging', which espouses school choice and childcare as a key factor in the processes via which individuals and households elect to belong to particular people(s) and place(s). Crucially, these daily population movements within and between towns and cities beg the question: are these 'to-ing and fro-ing' moves a sort of contemporary form of internal migration, albeit on a temporary basis, which do not require the relocation of the family? Conceptually, such questions warrant the attention of migration scholars to reconsider what constitutes internal migration in light of changing perceptions of daily commuting distances and temporalities, and journeys to school.

\section{Moving house/home for the 'right' school (catchment area)}

Another option for parents seeking to gain access to high-quality education for their children, if the 'right' school is not available in close proximity or within reach of their current place of residence, is to sell-up and move to another school catchment / place of residence that will provide access to the perceived 'right' type of school (Butler and Robson, 2003a; 2003b). Relatively high levels of economic capital and issues of power in the housing market will be clearly essential here to facilitate a move into an exclusive residential move. As Butler, et al. 
(2007, p. 25) assert: 'Moving house is a strategy that one would expect the middle class parents to be more likely to be able to adopt than parents of a lower social class.' Indeed, Butler et al. argue that moving house in this way is 'an important weapon in the armoury of middle class strategies over school choice' (ibid.).

These exclusionary social practices are exemplified by Burgess, et al. (2011, p. 532), who comment: 'Evidence suggests that the proximity criteria have increased house prices in desirable catchment areas, which effectively prohibits access for pupils from less advantaged families, who are priced out of the market.' From their analysis of the Millennium Cohort Study, Burgess, et al. (2011) conclude that: 'School choice in England is certainly partially determined by the ability of parents to buy more expensive houses near desirable schools' (p.533). In this way, it can be argued that the internal migration of middle class families into relatively high cost neighbourhoods is a pivotal factor in perpetuating how: 'Persistent residential social segregation is part of the background to unequal opportunities for poor and rich families to access high-quality schools' (Allen, Burgess and McKenna, 2012, p. 149)

Butler, et al. (2007) suggest that there are some important lifecourse factors here associated with education-induced movements for such families. It is argued that 'in gentrified areas of inner London education concerns featured low on initial reasons for moving into an area, but become dominant ones once children enter the household', and especially when 'the eldest child approaches the primary/secondary transition' (p.10). Butler, et al. (2007) infer this event as the key 'moment' when the household either moves residence, seeks private education and/or undertakes relatively long-distance internal daily mobility practices. Interestingly, and contrarily, Allen, Burgess and McKenna (2010, p. 20) affirm that residing in an advantageous location 'derives from families being in the right place before the relevant child is aged 5', and that 'house-moves of families during school years only make a small contribution to this difference [inequalities in access to high-quality schools]' (ibid). There are some important parallels here to McDowell, et al.'s (2006) comment that: 'pre-school childcare also figures in locational choices and in urban differentiation, leading to different traditions of caring / mothering in different neighbourhoods in London.'

Such studies emphasise how exclusive education markets and school catchment areas stimulate the internal migration of middle-class families with children both within and between locations. This is typified by Allen, Burgess and McKenna (2012) in their study of the impact of a reformed school admission system in Brighton and Hove. Investigating the effects of the implementation of a lottery-based school allocation process, alongside the formation of new school catchment areas, Allen Burgess and McKenna conclude that they 'expect [affluent] families to relocate and house prices to adjust in response to the re- 
drawing of catchment boundaries' (p. 164). Yet, understandings of these links between migration and residential decision-making that are mainly induced by education-related aspirations are not well established. As Raveaud and van Zanten (2006, p. 109) claim, the links between 'residential choice and choice of the local school' have been under-researched in the UK, especially, as we would argue, outside of London.

Positively, one recent contribution that progresses understandings of these links is provided by Francis and Hutchings (2013), based on an analysis of an on-line survey by YouGov across England (with 1,173 parents). It is shown that $32 \%$ of professional parents with children between 5-16 years of age from this sample have undertaken residential migration that was influenced by the presence of a good school, and $18 \%$ had explicitly moved to gain access to a specific school in a defined catchment area. While the equivalent shares for working class parents were c. $14 \%$ and $8 \%$, this study did not differentiated geographically other than in some instances between London and the rest of the country.

Butler, et al. (2007) also shed light on these internal migration processes, focussing on London: 'It should be noted that good schools are more likely to attract parents who are prepared to move residence to be nearer the school' (p. 25). Likewise, McDowell, et al. (2006) identify 'access to schooling, as a key part of the reasons for choosing to live in a particular urban neighbourhood', and contend that 'the residential location of families within urban areas will have a key effect on the range of options open to middle-class parents and vice versa' (p. 2163).

Interestingly, it would appear that sought-after schools in some distinct catchment areas have become over-saturated and exclusive, leading to the displacement of both working class and middle class residents. A number of recent studies bear out this trend. First, responding to the so-called 'education crisis' in London, Butler, et al. (2007, p. 8) report the growing incidence of middle class households: 'in desperate situations, moving home (even temporarily) to achieve access to favoured schools'. Indeed, Butler et al. point to the outmigration of middle class households from London, and portray a tension which is tied to a 'desperate trade-off between the attractions of remaining in a mixed and vibrant inner city environment near to work and cultural activities and concerns about social reproduction which points to a flight to the suburbs and beyond' (p. 10).

These findings parallel Bridge's (2006) study of gentrifiers with children in Bristol, which is one of the few case studies outside London. Gentrifier households were found to be tradingoff the advantages of inner urban living because the predilection for their children to attend high-performing schools often resulted in out-migration to suburban or rural areas. In a more recent study, Butler, Hamnett and Ramsden (2013, p. 556) pin point that 'incoming middle 
classes in the Victoria Park area of Inner East London have displaced not only existing poor residents but also many of the less affluent middle class from the favoured state schools in the area by adopting some schools and avoiding others'. A key explanatory factor here is referred to as the 'dichotomisation of schooling', with preferred schools being praised to the 'high heavens', and the 'shunned schools' being 'disparaged and deemed unacceptable' (ibid.). The growing constraints in exclusive housing and education markets witnessed by middle class households is also reflected in McDowell, et al.'s (2006, p. 2170) study, which describes the emergence of 'less affluent fractions of the middle class starting their housing and family careers now have to look elsewhere'. Clearly, the challenge for scholars of migration is to identify the places of destination and the importance of alternative provisions of school education within the migration and residential decision-making processes of middle class households that are moving away from the saturated education and housing markets of London (and other metropolitan) centres to access the 'right' schools'; a theme which is the focus of the next section.

\section{And 'beyond the urban': moving to the 'right' rural school}

Most previous research on the impacts of school choice and school catchment areas on internal migration has tended to be predominantly urban in its focus. However, recent studies have begun to examine the effects of middle classes families being 'pushed' away by the constraints of saturated, exclusive schools catchment areas, and attracted by the availability of high-quality school places in rural catchment areas (Walker and Clark, 2010). The appeal of rural residence is compounded by idyllic representations of rurality (peacefulness, safety, less crime, healthy environment, sense of community), with studies illustrating that rural places appeal to families with children because they are a good place to raise children (Halfacree, 1993).

One study typifying this direction of research is Smith and Higley's (2012) investigation of families moving out of London to Cranbrook in Kent, South East England, in their pursuit of high-quality rural schools. Smith and Higley reveal how in-migrant households, termed rural gentrifiers, are tapping into well-established 'rural expressions of circuits of education' within the locality, with the appeal of high performing preparatory and secondary schools, and with the added advantage of high-quality 'second choice' schools as an important 'safety net' if their first choice of school is not realised. Smith and Higley show how these migration flows are also bound-up with a (re)prioritisation of the family and the appeal of domesticity, with one partner stepping out of the formal labour market to spend more time with the children in the idyllic rural environment. 
Moreover, Smith and Higley reveal that such education and familial-led migrations out of the global city of London also stimulate the in-migration of grand-parents into Cranbrook to be nearer their sons/daughters and grand-children. The case study of Cranbrook thus serves to demonstrate how education-led forms of migration can have considerable knock-on effects, related to the extended family, and can spark other forms of internal migration that are motivated by combinations of different aspirations.

\section{Higher education and (transient) internal migration}

A fundamental component of the (re)production of [higher] education institutions, according to Holloway and Jöns (2012, p. 485), is the 'incoming and outgoing mobility of its students and staff'. Indeed, the UK system of higher education is generally predicated on an underlying assumption that young people will move away from their parental / guardian home and migrate to another region to undertake their university studies (Chatterton, 1999; 2010), thereby acquiring personal and cultural capital in the transition from youth to adulthood, as well as academic credentials and skills to enter the labour market (Smith and Sage, 2014). In a similar way to our discussion (above) of the linkages between the differential access to high-quality schooling and the triggering of internal migration, the hierarchical UK higher education system has stimulated inter-regional migration of generally young, single people from middle class households.

The state-led instigation of the expansion of higher education since the early 1990s, with a remit to achieve a $50 \%$ participation rate of young people by 2015 , further enhanced the inter-regional migration flows of young people to university towns and cities (Hinton, 2011). As rates of in-migration increased and more and more students tended to gravitate to specific neighbourhoods, driven by a variety of supply-demand relationships tied to local housing markets, student lifestyle orientations and normative expectations (Smith and Holt, 2007), many local neighbourhoods across the UK were transformed by processes of studentification (Hubbard, 2008). Clearly, what lies at the heart of these processes of urban change are the transitory migration flows of young people, moving into and out of local neighbourhoods to the chime of the academic calendar and semesters/terms.

At the same time, it is important to recognize that the social geographies of university students are highly uneven, with university towns and cities hosting the most elite, prestigious universities most likely to have higher proportions of individuals from wealthy households registered at the institution. Of particular relevance here is Hoare and Johnston's (2011) extremely insightful discussion of the application and allocation processes of places at higher education institutions in the UK, 'whereby a place in a UK university has to be 
earned through open competition through the world's largest centralized admissions service for higher education' (p. 23). Although Hoare and Johnston recognize that 'students can apply to any course at any university irrespective of where they live, each of which has the autonomy to accept or reject them', acceptance is based, in part, on 'the applicant's academic record at school' (ibid.). As a result, Hoare and Johnston describe how the allocation processes of 'elite universities' 'are thus likely to disadvantage the lower-attaining widening-participation students from educationally disadvantaged backgrounds' (p.24). The implications of this allocation system on the reproduction of social class privilege and social mobility are profound as elite universities 'send their graduates disproportionately into prestigious and highly paid professional careers' (ibid.).

Despite the acknowledgement of the dominance of university students moving sub-nationally at a regional scale, research on the links between migration and higher education in the UK focuses predominantly (with one or two exceptions) on international migrants (e.g. King and Ruiz-Gelices, 2003; Waters and Brooks, 2011). Although this research focus is clearly important, it is also imperative to extend understandings of student migration by paying more attention to sub-national migration flows of students. Of course, the latter populations will include some of the former populations as international students move between institutions/places within the UK, for example, as part of the process of shifting from undergraduate to postgraduate study, while outgoing UK students are most frequently recruited from those more affluent strata of the population that accessed university via private education, thereby (re)producing their membership in what Findlay, et al. (2012, p. 121) call the 'transnational capitalist class'.

To date, there are limited studies of the internal migration of university students in the UK, despite inter-regional migrants dominating the make-up of the majority of university student populations in the UK (Smith, 2002). To illustrate the scale and magnitude of these migration flows metaphorically, Smith (2009) argues that inter-regional student migration is equivalent to the annual depopulation/repopulation of Birmingham (c. 1 million inhabitants). The general lack of attention and paucity of analyses of inter-regional flows of university students is to some extent surprising, but it is clearly tied to the lack of robust migration datasets reporting student migration in accurate and comprehensive ways (Champion and Coombes, 2007). Recently, developments and accessibility of UK census data and other datasets such as HESA datasets has enabled scholars to start to grapple with the sub-national migration flows of university students. A seminal paper in this vein is Duke-Williams' (2008) novel deployment of UK census data, using 2001 Special Migration Statistics, in conjunction with Census Aggregate Statistics and 1991 Small Area Statistics to investigate migration flows of wards with relatively high concentrations of students. Taking studies of studentification as a 
starting point (Smith, 2005), one of Duke-Williams' (2008) key findings is as follows: 'The general process of student migration is thus not only one that can be seen through the perspective of studentification; it is also one that acts on a wider basis to relocate people around the country' (p. 1846). Moreover, Duke-Williams argues that higher education 'is a mechanism through which the South East of England gains qualified workers' (p. 1826). As a result, Duke-Williams identifies a mismatch between sending and receiving places, revealing that 'districts sending students away to university... did not see a direct return on that investment: there was not a corresponding counterflow of qualified people back to these districts' (p. 1846) (see also Faggian and McCann, 2009).

Another original study using UK census microdata that has some parallels with Holdsworth's (2006; 2009a; 2009b) and Christie's (2007) findings about the impact of social class privilege on different propensities to move to another region to study at a university or stay-at-home, is Finney's (2011) investigation of the internal migration of young adults and ethnicity. Crucially, Finney reveals that although '[b]eing a student increases residential mobility for White British and Chinese young adults', studenthood 'reduces mobility for young adults from Black and South Asian ethnic groups (particularly for females in the Pakistani ethnic group)' (p. 455). These findings are particularly important in light of the lack of previous research on ethnicity, migration and higher education. There are numerous other gaps in our understandings of social difference and higher education migration from the perspective of students, for example, it is possible to pose questions about the linkages between sexuality, migration and higher education by examining whether more gay and lesbian students move inter-regionally to attend universities in so-called more gay and lesbian friendly places such as Brighton, Manchester and parts of London (Duncan and Smith, 2006).

Clearly, there is much more research that is urgently required in these fields of study on social difference, internal migration and higher education, including the links between student and graduate mobilities. A better understanding of internal student and graduate migration seems to be of prime importance in the light of Parkinson et al.'s (2006, p. 104) finding that universities can be regarded as 'the key to innovation in the city', particularly if they successfully recruit and retain university graduates. Their (im)mobility is currently reinforcing existing geographical inequalities as the UK Graduate Careers Survey 2012 showed that London remains 'the preferred employment destination for finalists', with half of the graduates hoping 'to work in the capital after graduation' (High Fliers Research Limited, 2012, p. 2). London was in fact 'the first choice at 25 out of the 30 universities included in the survey' and only finalists at Queen's University Belfast, Glasgow, Strathclyde, Lancaster and Liverpool aspired instead to work in their region of university study (ibid.). Hoare and Corver (2010) provided an even more detailed study, in which they identified clear winner and loser 
regions in regard to graduate labour recruitment when comparing UK students' transitions from home to university and from university to the labour market. Differentiating locals, returners, stayers and outsiders in inter-regional mobility from home to university and into the labour market, they identified London as the single winner region of graduate recruitment. Only Scotland as well as Yorkshire and the Humber achieved a balance between providing undergraduates and recruiting graduates, whereas the other nine regions lost more students than they gained graduates. The South East substantially increased its deficit from 1998-99 to 2001-02, while the North East, the East Midlands, and Wales reduced their deficit considerably, even if they depended to different degrees on locals and returners (Hoare and Corver, 2010, p. 484). In light of these important findings, we stress the need for more academic studies on the recruitment areas of universities and the differing success of university towns and cities in retaining university graduates because such studies would provide important insights into the future economic prosperity of different places within an increasingly competitive UK knowledge economy (Parkinson, et al., 2006).

\section{Beyond students: internal migration of teachers and academics}

Although we have in a sense focused on the 'consumers' of education in this chapter, there is also important research that needs to be undertaken with the producers of education. Accordingly, the final avenue of research we wish to discuss links pre-school, school and university education by directing attention to the spatial movements of those who teach at different levels in UK education. To an even larger degree than discussed in regard to student mobility, geographical interest in the career trajectories of school and university teachers has focused on their international mobility experiences (Appleton, Morgan and Sives, 2006; Jöns, 2011). This is best exemplified by the origin of the 'brain drain' debate because this term was first used in 1963 by the Evening Standard in response to a Royal Society report about the emigration of UK scientists to the United States and Canada in the 1950s and 1960s (Balmer, Godwin and Gregory, 2009). In other cultural contexts, geographical research has much more frequently studied internal 'brain drain' through career movements of school and university teachers between different educational institutions and regions (for an overview, see Meusburger, 1998). A comparable body of work focusing on the UK context is almost entirely absent, which prompts us to call for more research on internal migration behaviour of UK teachers and academics, considering institutions, towns, cities and regions.

Such a body of work could usefully draw on Hoare's (1994) earlier study on geographical mobility of academic staff within the UK in the late 1980s. This study found that local 
recruitment of academic staff across UK universities (as measured by the place of the undergraduate degree) decreased from $37 \%$ in the early 1960s (Robbins Report) to less than $20 \%$ in ten out of 13 established case study universities in the late 1980 s (Southampton being the youngest case study university). Peripheral universities in Belfast, Glasgow and Edinburgh recruited up to $40 \%$ of their academic staff among their own students, and localism tended to be generally higher in medical subjects and in research universities performing well in the research assessment exercise (Hoare, 1994, p. 148 and p. 157). Hoare's (1994) study therefore stressed that universities with high localism have 'a weaker intellectual resources base than those whose appointment practices are geographically more widespread' (pp.152-153). Drawing on Hoare's further insight of 'self-reinforcing advantages of student recruitment, quality graduate output and research expertise ... benefitting broadly the same university regions', namely those 'with the lowest dependencies on locally-trained graduates' (p. 159), we see the need for more and more recent studies about internal migration of UK academic staff, especially in the light of an increasing internationalisation of UK universities and potential changes related to more than three decades of research assessment exercises.

Examining the spatial career paths of UK teachers and academic staff in the UK and beyond will help to identify institutions and geographical places and regions that successfully attract the most proactive and/or productive teachers and academics and those who are struggling to do so. These career paths in education are most likely linked to the performance of schools and universities and therefore shape, as discussed above, wider internal migration patterns of the middle classes across the UK. Moreover, Meusburger's (1998) Germanlanguage account of geographies of education reviewed geographical studies in mainland Europe that identified a close link between the local presence of primary and secondary teachers and the cultural and socio-economic prosperity of rural areas, which further underlines the need for population geographers to understand processes of mobility and migration from the perspective of individual and collective career trajectories, within the UK economy and beyond. Accordingly, we argue that the inclusion of teachers' and academics' migration behaviour into a research agenda on 'Migration and Education' will substantially improve our understanding of the relationship between education, labour markets, and internal migration behaviour in the UK. In addition to the often but not always linear spatial career trajectories of teachers and academics between jobs, it also seems to be important to examine their short-term circulations within a job, for professional development, conferences and other meetings, as well as their commuting habits and patterns because both types of movement represent another constitutive part of internal migration related to the education sector. 


\section{Conclusion}

Despite almost two decades passing since Dobson and Stillwell's (2000) proclamation of the need to consider more fully the importance of education factors in the migration and residential decision-making of families, it would appear that the research agenda that they espoused is perhaps even more pertinent to the current context of competitive education and housing markets, and the willingness of individuals and families to relocate to access prized education spaces. To date, we would argue that there is a distinct lack of empirical evidence that comprehensively advances understandings of the links between education and internal migration in the UK, especially in places outside London. There is also a demand for improving our understanding about the connections between education and housing markets, and the movement of populations. This is best exemplified by Allen, Burgess and Key's (2010, p. 20) study because their findings contradict much of the existing academic scholarship by revealing that 'families do not appear to use house moves to optimize their school choice decision to the extent we might expect'. More distinct geographically differentiating perspectives might help to unravel such apparent contradictions between different case study contexts. Equally, there is a lack of empirical evidence to substantiate understandings of the impacts of higher education on internal migration, including the role that internal migration by university graduates, teachers and academics plays for shaping educational provision, internal migration of students and families, and the related prosperity of UK towns, cities, and rural areas.

With these overlaps between school and higher education in mind, we would suggest that there is value in transposing and extending Dobson and Stillwell's (2000, p. 400) set of research questions that they posed, to place a broader focus on education and migration per se. In this vein, we propose the following research questions for future studies:

- How frequently do considerations of schooling and higher education constitute the primary determinant of a decision to move home? How often do they constitute a determinant at all, and how often are they an adjunct of another primary determinant?

- $\quad$ To what extent is the perceived quality of schooling and higher education a driver of internal migration and to what extent a barrier? On what experience, knowledge or criteria are perceptions, evaluations and decisions based?

- How often is the destination of a move chosen specifically in order to live in the catchment area of a particular school, or to study at a specific university? How have the perceived merits of that school/university been identified?

- Do schooling or university considerations inhibit household moves? Are they a key factor in respect of the residential area attachments of some ethnic minority groups or other axes of social difference? 
- $\quad$ How does schooling or university affect career decisions among mobile workers? Which places and regions are successful in attracting and retaining different types of graduates and which are not? How do internal migrations of graduates link to international movements?

- What are the career trajectories of teachers and academics in UK education? How do teachers and academics decide where to move for their job? To what extent do they engage in commuting for longer distances between different homes or between home and work, and what role does circular mobility for learning and teaching play for them?

With the forthcoming release of the migration datasets from the 2011 UK census, scholars of migration and those concerned with geographies education are well primed to address some of these important issues of education-led migration, population change, social inequalities in housing and education markets, the growing segregation of society, and the ways in which education migration mediates the increasing geographic concentrations of social groups based on affluence and poverty. Some of the questions raised above may, however, best be answered through independent surveys, qualitative interviews and/or a multi-method approach.

Conceptually, our research agenda on migration and education encourages three lines of thought for future development. First, we would urge researchers of education and migration to follow the lead of McDowell, et al. (2006) in recognising a more holistic perspective of the inter-connections between education and migration across the lifecourse. It would be beneficial to embed childcare and higher education more explicitly into understandings of 'circuits of education'. As McDowell et al. stress, 'access to the 'right' school and later university are matters of considerable concern' (p. 2167). Important here are the ways in which inter-generational social class privilege is reproduced via internal migration to access exclusive forms of school and higher education. Studies of gentrification have shown, for example, the importance of "networks of university graduates who move through life in a kind of 'bubble' which their children are apparently inhabiting in similar sorts of ways' (Butler, 2003, p. 2483).

Second, we propose to study three spatial migration trajectories more explicitly, in the form of linear, reciprocal and circular moves, because these do not only help to systemize spatial mobility for knowledge production (Jöns, 2002, p. 8) but also to compare different forms of internal migration for education at the levels of pre-school, school and university education. For example, linear moves between two places involve residential moves into catchment areas of good schools; student mobility from home to university or from undergraduate to postgraduate studies between different universities; as well as career migration of teachers and academics. Reciprocal moves include commuting practices between two family homes 
that were either set up to guarantee access to the best schools or to enable double-career relationships of teachers and academics. Circular moves can be examined in the form of daily movements between home and schools by students, teachers and academics; as circular migration of students from their home region to university and back during vacations; and as return migration of university graduates to their home region or for teaching jobs in their place of university study (after teacher training elsewhere). We argue that such a conceptualisation of linkages between migration and education, which is based on the main spatial direction of the planned or actual migration and can take various forms along the continuum of temporary to permanent mobility in all three spatial trajectories, can help to identify areas that benefit more from incoming, outgoing, reciprocal or circular forms of migration than others and therefore empower migration scholars and policy makers to assess potential implications for the future economic, social and cultural prosperity of rural, rural-urban and urban areas in the UK.

Third, we support King and Skeldon's (2010, p. 1619) call for bridging studies of international and internal migration as two fields that are 'characterised by different literatures, concepts, methods and policy agendas'. While such an integration of different geographical scales might not always be relevant, we agree with these authors that 'internal and international migrations are generated by similar forces and, despite the crossing of an international boundary as an important distinguishing feature, close linkages exist between them' ( $p$. 1622). Education-related migration might be a useful starting point for comparative studies on internal and international migration because study abroad has become an integral part of the curriculum in some UK schools and most UK universities. Moreover, the majority of geographical research on the linkages between education and migration has focused on international student mobility and transnational academic mobility, which might generate useful synergy effects for conceptual considerations and empirical studies that draw attention to internal migration without neglecting the previously highlighted perspective. This is best exemplified by Findlay et al.'s (2012, p. 121) visual conceptualisation of ' $[\mathrm{t}]$ ransnational and national student flows in relation to the differentiation of higher education and the global labour market' because this stresses the important role of elite private schools as the most important springboard for access to world class education and transnational careers.

To conclude, this chapter has demonstrated how both school and higher education markets have become more competitive and exclusive in light of legislative changes that have supposedly fostered more choice, performance evaluation and competition under the guise of neoliberal agendas. One of the major unintentional consequences of these changes to educational systems in the UK has been the more pronounced internal migration of middle- 
class individuals and families which, in turn, has led to dramatic implications for local housing markets and reconstituted many local population structures, thereby transforming the social class, ethnic/racial, cultural, demographic, familial and gender characteristics of some local communities and neighbourhoods. The ways in which the neoliberalisation and deepening exclusivity of schools and higher education has spawned processes of internal migration in the UK cannot be over-stated. Migration scholars have a pressing remit to investigate why, how, where and when the quest to access high quality schools and/or higher education triggers sub-national internal migration, and becomes one of the key factors in the widening socio-spatial divisions within UK society. 